\title{
Erratum to: Evaluation of the safety and efficacy of metoprolol infusion for children and adolescents with hypertensive crises: a retrospective case series
}

\author{
Rola Saqan $^{1}$ - Hanan Thiabat ${ }^{1}$
}

Published online: 22 September 2017

(C) IPNA 2017

\section{Erratum to: Pediatr Nephrol}

https://doi.org/10.1007/s00467-017-3720-6

Owing to an error in typesetting, Fig. 1 was omitted and Fig. 2 was duplicated in its place. Both figures and their legends are reproduced here.

The original publication has been corrected in this respect.

The online version of the original article can be found at https://doi.org/ 10.1007/s00467-017-3720-6

Rola Saqan

rssaqan@just.edu.jo

Jordan University of Science and Technology, Irbid, Jordan

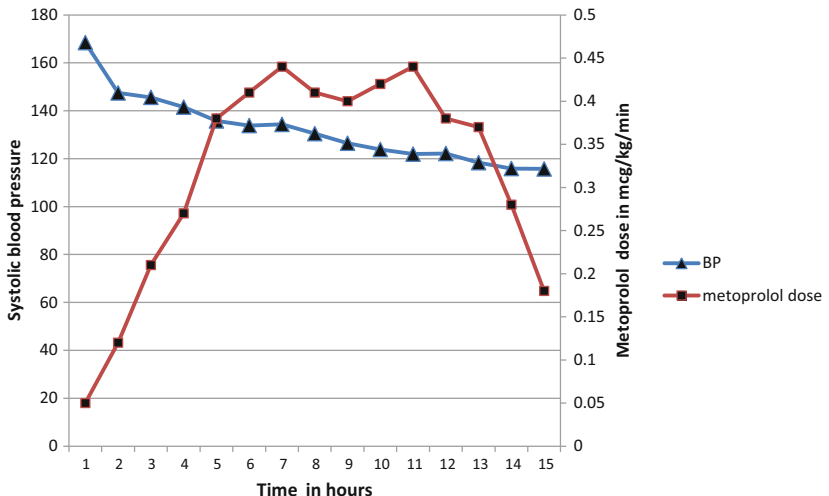

Fig. 1 The relation between systolic blood pressure and metoprolol dose. The average blood pressure and the average metoprolol dose used over time are shown 
Fig. 2 Drop in blood pressure (BP) in all 13 subjects over the first $24 \mathrm{~h}$ of metoprolol infusion

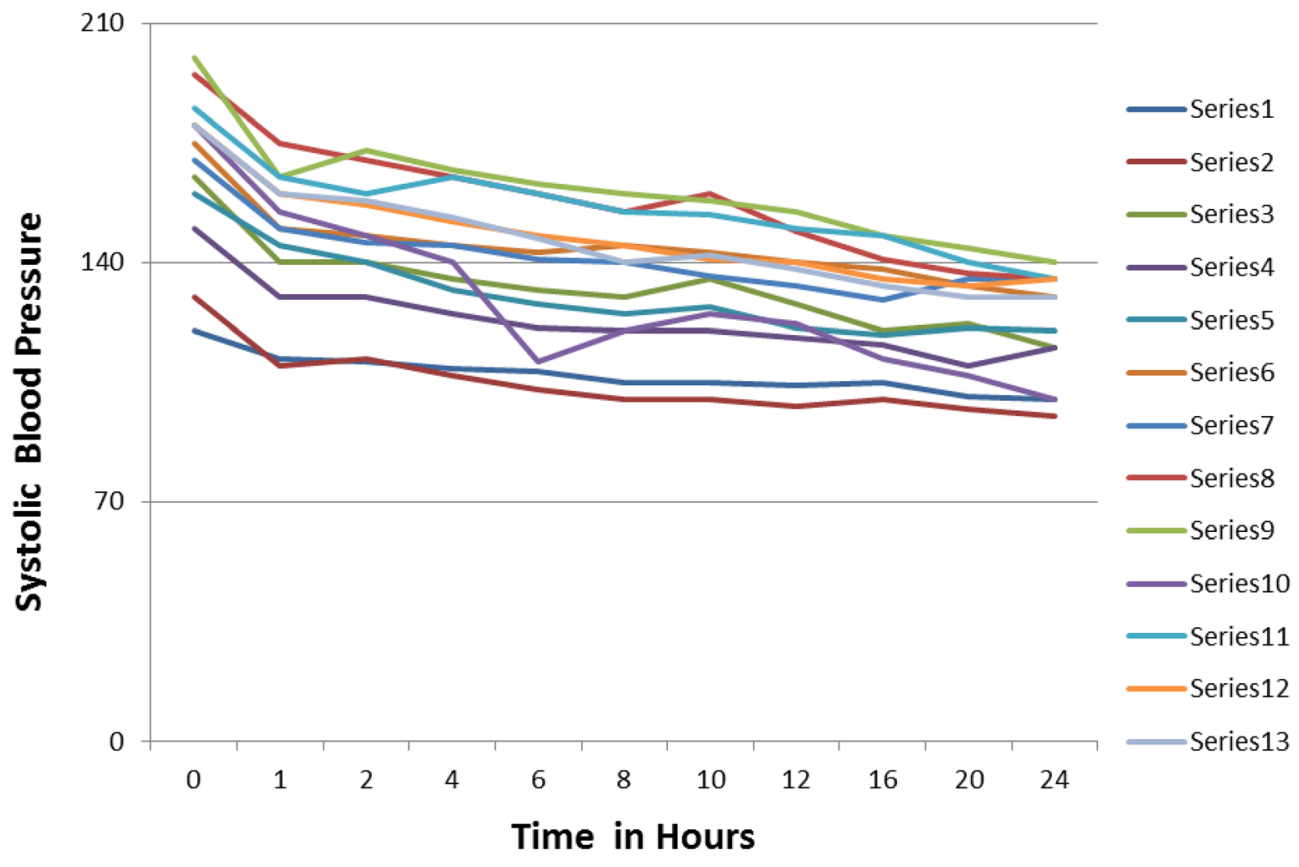

